\title{
APPLICATION OF QUANTUM CHEMICAL, NOISE AND THE ELECTROCHEMICAL FREQUENCY MODULATION TO INVESTIGATE THE ADSORPTION AND CORROSION INHIBITION BEHAVIOR OF 2-AMINO-6-HYDROXYBENZOTHIAZOLE FOR STEEL API X80 IN ACIDIC SOLUTION
}

\author{
I. DANAEE * AND P. NIKPARSA \\ Abadan Faculty of Petroleum Engineering, Petroleum University of Technology, Abadan, Iran.
}

\begin{abstract}
Different theoretical, electrochemical and surface techniques were applied to study the corrosion inhibition effects of 2-Amino-6-hydroxybenzothiazole in 5\% HCl solution. The density functional theory was carried out and quantum chemical factors like the energy gap, energy of highest occupied molecular orbital, the energy of lowest unoccupied molecular orbital, the fraction of electron transferred, and Mulliken charges have been calculated. In addition, according to quantum calculation, $\mathrm{S}$ atom in 2-Amino-6-hydroxybenzothiazole indicated more tendency for electrophilic attack in adsorption. The main reason for high inhibition efficiencies in very low concentrations is the planar and simplicity of inhibitor structure which leads to increasing the efficiency of adsorption by functional group e specially sulfur. Electrochemical frequency modulation and potentiodynamic polarization indicated that this material has excellent inhibiting features in very low concentrations. The influence of DC trend on the explanation of electrochemical noise data was evaluated by polynomial fitting and the optimum polynomial order $\mathrm{m}=4 \mathrm{mas}$ obtained. Noise resistance and the inhibition efficiency was calculated and compared in different methods. The theory of shot noise in frequency domain was used to obtain the electrochemical event charge. The corroded surface of steel in the absence and existence of thiazole compound was studied by Atomic force microscopy.
\end{abstract}

Keywords: Noise; Electrochemical frequency modulation; DC Trends, Power spectral density; AFM; Density functional theory.

\section{INTRODUCTION}

Several electrochemical and quantum chemical methods are widely used to investigate the corrosion inhibition characteristics of materials. Electrochemical frequency modulation (EFM) is a fast non-destructive method for measuring corrosion rate [1-3]. Similar to EIS, this method used small signal ac method in which two ac voltage are summed and acted on an electrode. Though simple in employing and concept, EFM results a notable amount of information on the parameters of corrosion containing Tafel constants, corrosion rate and causality parameters. The corrosion rate is computed from the corrosion current density, which is determined using EFM [4-7]. One of the benefits of the EFM method is its short time period.

Electrochemical noise is attractive in corrosion investigations and monitoring because of its non-intrusive behavior. This method has been applied in controlling corrosion, assessment of localized corrosion, study of organic coatings, and assessment of inorganic anticorrosive pigments. In recent years, EN has been used to study the inhibition effect of different organic inhibitors such as azoles and imidazoline derivatives, amino acids and drugs in acid solutions [8-10]. In addition, types of inhibitor adsorption and isotherms and pitting behavior of metals were investigated by EN [8-10].

The electrochemical current and potential noise comprises valuable data about the ongoing procedure in the electrochemical system, which can be studied in the frequency domain and the time domain. Analysis of the time domain in electrochemical noise data contains computing the noise resistance. It has been demonstrated that the noise resistance was in a good accordance with polarization resistance which can be measured by means of other electrochemical approaches like EIS and polarization. Actually, noise resistance is a particular type of polarization resistance, which is called statistical polarization resistance $[11,12]$.

Acid solutions are extensively applied in industry, including industrial acid cleaning, acid pickling, acid descaling and oil well acidizing [13-15]. Well stimulation or acidizing is a process to improve oil and gas production that throughout this procedure, aggressive fluids are introduced into contact with metal structure. Acid is forced over the well for reacting with rocks (dolomite, calcite and limestone) through chemical reactions and dissolving them, opening new flow channels and enlarging bores $[16,17]$. The most frequently utilized acid in acidizing process is $\mathrm{HCl}$ [18]. Hydrochloric acid is more cost-effective and reacts quickly with the rocks, but is extremely corrosive for metal structure. Therefore, the acid has to be combined with corrosion inhibitors in such a way that the materials surface can be preserved against corrosion. Consequently, corrosion inhibitors are one of the main groups of chemicals materials used as additives for acidic recovery fluids in oil industry. Numerous corrosion inhibitors have been introduced to be useful in many acid solutions with diverse levels [1921].

The usage of organic molecules is a most useful approach to protect materials against the corrosion and it is becoming progressively common. These materials generally are adsorbed on the materials surface and block the active sites of corrosion. Four kinds of adsorption may occur by using organic molecules at interface of solution/metal: (1) interaction between metal and the unshared electron pairs in the molecule; (2) electrostatic attraction of the charged metal and the charged molecules; (3) interaction between metal and $\pi$-electrons; (4) combination of (1) and (2) [19-21].

Generally the organic compounds with hetero atoms such as $\mathrm{N}, \mathrm{S}, \mathrm{O}$, and $\mathrm{P}$ are observed to act as very useful corrosion inhibitors [22-24]. The performance of these organic compounds is affected by electron density available around the hetero atoms, amount of available active centers for adsorption and their charge density, dimension of molecular, adsorption type, and creation of metallic complexes $[25,26]$.

Organic molecules inhibition performance depends primarily on the electronic features (like the Frontier orbital energies, energy gap, dipole moment, etc) and natures of the adsorbed layers on the surface of the metal [27]. Quantum chemical calculations, as influential theoretical tools in determination of molecular structure, have been used to associate the inhibition performance to the molecular features of materials. For instance, it has been found that, molecules with small band gap energies are extremely reactive and are effective inhibitors $[27,28]$.

API X80 steel is one of the developed materials for production of gas transportation pipelines and oil and gas well. The aim of the current research is to assess the corrosion behavior of $\mathrm{X} 80$ steel in $\mathrm{HCl}$ solutions comprising 2Amino-6-hydroxybenzothiazole using electrochemical methods. $5 \% \mathrm{HCl}$ was employed to simulate the oil well acidizing fluid. 2-Amino-6hydroxybenzothiazole is a simple molecule with high inhibition behavior in very low concentrations. This is the predominance of studied inhibitor in comparison with other complicated inhibitors. Diverse aspects of electrochemical noise are emphasized to study the corrosion inhibitors. Additionally, it is proposed to seek the relationship between EN and also its power spectral density data with the parameters achieved from EIS and polarization curves. Atomic force microscopy was utilized to investigate microstructure of steel surface. Theoretical calculation is also performed for finding a relation between molecular and electronic structures of the studied inhibitor and its inhibition performance. 


\section{EXPERIMENTAL DETAILS}

\subsection{Materials}

The steel samples utilized in electrochemical determinations were mechanically cut into $1 \times 1 \times 0.5 \mathrm{~cm}^{3}$, and introduced into polyester resin leaving simply $1 \mathrm{~cm}^{2}$ of the surface area exposed to electrolyte. The working electrode surface was mechanically abraded with 1000,1200 , and 2000 grades of emery paper and washed with distilled water prior all electrochemical tests. The experiments were carried out in 5\% $\mathrm{HCl}$ solution comprising different levels of inhibitor.

\subsection{Methods}

The electrochemical tests were performed by computer controlled Autolab potentiostat/galvanostat. Prior electrochemical test, the samples were submerged in a test solution at open circuit potential $\left(E_{\mathrm{OCP}}\right)$ for $20 \mathrm{~min}$ to achieve a steady state. To perform polarization, EIS and EFM tests, a three electrode cell containing the X80 steel sample as working electrode, a Platinum sheet as counter electrode and a saturated calomel electrode as reference was utilized. Polarization curves were provided at a scan rate of $1 \mathrm{mV} \mathrm{s}^{-1}$ from $-700 \mathrm{mV}$ to $200 \mathrm{mV}$ vs. SCE. Electrochemical Frequency Modulation (EFM) was performed with two frequencies 2 and $5 \mathrm{~Hz}$ and the base frequency was $1 \mathrm{~Hz}$. The perturbation signal with amplitude of $10 \mathrm{mV}$ was used for both perturbation frequencies of 2 and $5 \mathrm{~Hz}$. EIS measurements were executed at OCP in the frequency range $100 \mathrm{kHz}$ to $0.01 \mathrm{~Hz}$ by a sine wave of $10 \mathrm{mV} \mathrm{AC}$ amplitude. Experimental impedance was fitted to the suggested equivalent circuit and the corrosion parameters were obtained $[29,30]$.

The simultaneous measurement of electrochemical current and potential noise was performed in corrosive solution with two similar steel electrodes with the same area and a calomel reference electrode which was located between the two steel electrodes. Electrochemical noise data with resolution $0.1 \mu \mathrm{V}$ and $1 \mathrm{nA}$ was obtained during $1024 \mathrm{~s}$ at $0.2 \mathrm{~s}$ interval. This caused a frequency in the range of close to $1 \mathrm{mHz}$ to $0.5 \mathrm{~Hz}$ measured by the expressions $f_{\max }=1 / 2 \Delta t$ and $f_{\min }=$ $1 / N \Delta t$ where $\Delta t$ is the specimen interval and $N$ is the total number of data recorded. All tests were performed at temperature of $25^{\circ} \mathrm{C}$.

The geometry of 2-Amino-6-hydroxybenzothiazole was optimized without any symmetry constraint using density functional theory (DFT) with at B3LYP level. B3LYP consists of the Beck's three parameters exchange functional along with the Lee-Yang-Parr nonlocal correlation functional. DFT is a very useful approach to calculate the structural and electronic properties of different compounds [31-33]. Atomic orbitals were described by means of $6-31 \mathrm{G}(\mathrm{d}, \mathrm{p})$ basis set including polarization functions. Each of these computations was performed in Gaussian software.

$\mathrm{E}_{\text {Hомо }}$ and $\mathrm{E}_{\mathrm{LUmO}}$ stand for the energy of the highest occupied and lowest unoccupied molecular orbitals respectively. The given factors like electron affinity $(A)$, Ionization energy $(I)$, global hardness $(\eta)$, softness $(S)$ and electronegativity $(\chi)$ were evaluated using the energy of HOMO and LUMO (Eqs. 1-10). The values of $\chi \mathrm{Fe}$ and $\eta \mathrm{Fe}$ were set to 0.2572 and 0 hartree respectively, for bulk Fe atom based on the Pearson's electronegativity scale. The above-mentioned parameters were computed based on the subsequent expressions [34]:

$$
\begin{aligned}
& I: \text { ionization energy } \simeq-E_{\mathrm{HOMO}} \\
& A: \text { electron affinity } \simeq-E_{\mathrm{LUMO}} \\
& \Delta E_{\mathrm{Gap}} \text { : the energy gap }(\mathrm{eV})=E_{\mathrm{LUMO}}-E_{\mathrm{HOMO}} \\
& \chi: \text { absolute electronegativity }=(I+A) / 2 \\
& \eta: \text { Global hardness }=(I-A) / 2 \\
& S: \text { global softness }=1 / \eta \\
& \omega: \text { Global electrophilicity index }=\mu^{2} / 2 \eta \\
& \Delta E_{\mathrm{Back}} \text {-donation: the back donation }=-\eta / 4
\end{aligned}
$$

$\Delta N$ : the fraction of electron transferred $=\left(\chi_{\mathrm{Fe}}-\chi_{\text {inh }}\right) / 2\left(\eta_{\mathrm{Fe}}+\eta_{\text {inh }}\right)$

$N$ : Global nucleophilicity index $=1 / \omega$

\section{RESULTS AND DISCUSSION}

\section{1. Computational investigation}

$\mathrm{Ab}$ initio quantum chemical computation using DFT technique is employed to study the inhibition behavior of 2-Amino-6-hydroxybenzothiazole molecule. Optimized structure and frontier molecule orbital density distributions of the inhibitor: HOMO and LUMO are depicted in Fig. 1.

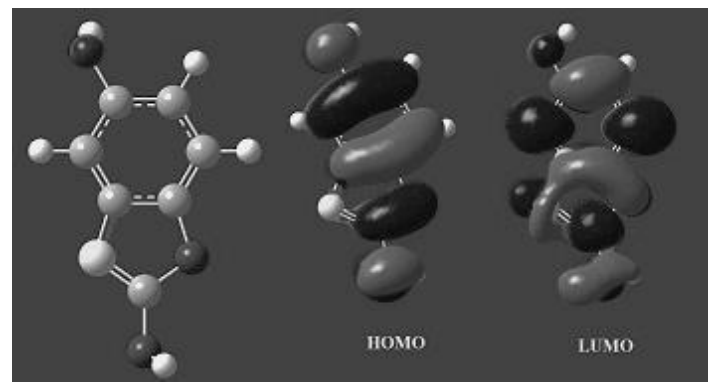

Figure 1. The optimized molecular structures (where red: oxygen, blue nitrogen, gray: carbon and white; hydrogen), HOMO and LUMO of the neutral inhibitor molecule using DFT/B3LYP/6-31G (d,p).

As it is observed from Fig. 1, the electron density corresponding to HOMO and LUMO distributed over the benzene rings, nitrogen and oxygen atoms. Table 1 shows the detailed data of quantum chemical computations.

Table 1. Calculated quantum chemical indices of 2-Amino-6hydroxybenzothiazole.

\begin{tabular}{|l|l|c|}
\hline Highest occupied molecular orbital $(\mathbf{e V})$ & $E_{\text {НОМО }}$ & -5.35 \\
\hline Lowest unoccupied molecular orbital $(\mathbf{e V})$ & $E_{\text {LUMO }}$ & -0.16 \\
\hline Energy gap $(\mathbf{e V})$ & $\Delta E_{\text {Gap }}$ & 5.18 \\
\hline Ionization energy $(\mathbf{e V})$ & $I$ & 5.35 \\
\hline Electron affinity $(\mathbf{e V})$ & $A$ & 0.16 \\
\hline Global softness $(\mathbf{e V})^{-\mathbf{1}}$ & $S$ & 0.38 \\
\hline Global electrophilicity index $\boldsymbol{\omega}(\mathbf{e V})$ & $\omega=\mu^{2} / 2 \eta$ & 12.20 \\
\hline Global hardness $(\mathbf{e V})$ & $\eta$ & 2.59 \\
\hline Back-donation Energy $\mathbf{( e V )}$ & $\Delta E_{\text {Back-donation }}$ & -0.64 \\
\hline Global electronegativity $(\mathbf{e V})$ & $\chi$ & 2.76 \\
\hline The fraction of electron transferred & $\Delta N$ & 0.82 \\
\hline Global nucleophilicity index $\boldsymbol{N}(\mathbf{e V})$ & $N$ & 0.08 \\
\hline
\end{tabular}

$\mathrm{E}_{\text {номо }}$ of the inhibitor represents its ability for donating electrons to suitable acceptor molecule of low empty molecular orbital energy i.e. it reflects oxidation. Also, $\mathrm{E}_{\mathrm{LUMO}}$ stands for the lowest unoccupied molecular orbital which is defined as a tendency of the molecule to receive electrons from the metal d-orbitals. Agreeing with Lukovits's research [35] if $\Delta \mathrm{N}<3.6$, the inhibition performance enhances with rising electron-donating ability at the surface of metal.

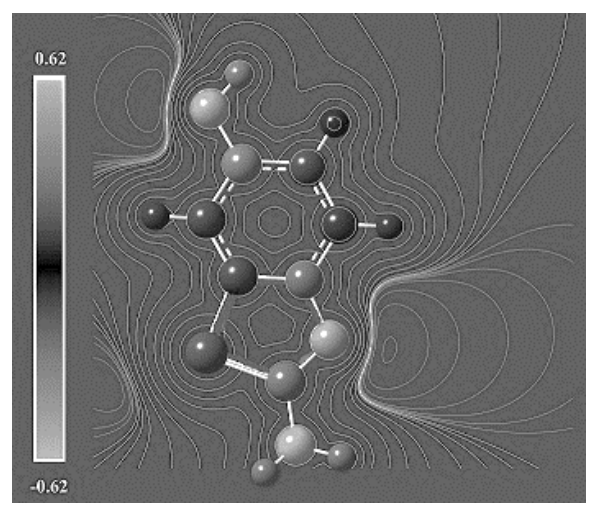

Figure 2. The Muliken charges population of 2-Amino-6-hydroxybenzo thiazole inhibitor. 
Fig. 2 shows the Muliken atomic charges calculated for the given inhibitor. It is observed that all the hetero atoms and some carbons atoms have negative charge centers which could offer electrons to the mild steel surface to form a coordinate bond.

In addition, Fukui functions were assessed by Mulliken population analysis of atoms in the inhibitor (Eqs. 11 and 12) based on the electron transfer direction.

$$
\begin{array}{rlrl}
f_{k}^{+} & =\left[q_{k}(N+1)-q_{k}(N)\right] & & \text { (for nucleophilic attack) } \\
f_{k}^{-}=\left[q_{k}(N)-q_{k}(N-1)\right] & & \text { (for electrophilic attack) }
\end{array}
$$

where $q_{\mathrm{k}}$ refers to the gross charge of atom $\mathrm{k}$ in the molecule. $\mathrm{N},(\mathrm{N}+1)$, and $(\mathrm{N}-1)$ correspond to the number of electrons, an anion with an electron entered to the LUMO, and cation with an electron exited from the HOMO corresponding to the neutral molecule [36]. These parameters can be used to represent reactive regions (the areas in a molecule vulnerable for electrophilic and nucleophilic attack) in a molecule. The Fukui functions over the heteroatoms, to simplify the discussion, are summarized in Table 2.

Table 2. Calculated Mulliken charges and Fukai functions for 2-Amino-6hydroxybenzothiazole.

\begin{tabular}{|c|c|c|c|c|c|}
\hline Atom & $\mathbf{q}_{\mathbf{k}}(\mathbf{N}+\mathbf{1})$ & $\mathbf{q}_{\mathbf{k}}(\mathbf{N}-\mathbf{1})$ & $\mathbf{q}_{\mathbf{k}}(\mathbf{N})$ & $\mathbf{f}_{\mathbf{k}}{ }^{+}$ & $\mathbf{f}_{\mathbf{k}}{ }^{-}$ \\
\hline $\mathrm{O}$ & -0.469714 & 0.009059 & -0.562356 & 0.092642 & -0.571420 \\
\hline $\mathrm{N}$ & -0.446909 & -0.015368 & -0.511596 & 0.064687 & -0.496230 \\
\hline $\mathrm{S}$ & 0.343560 & 0.044977 & 0.181587 & 0.161973 & 0.136610 \\
\hline $\mathrm{N}$ & -0.549523 & 0.021645 & -0.623441 & 0.073918 & -0.645090 \\
\hline
\end{tabular}

In these calculations, $\mathrm{f}_{\mathrm{k}}{ }^{+}$and $\mathrm{f}_{\mathrm{k}}{ }^{-}$are applied to show the site for nucleophilic and electrophilic attack, respectively. For the mentioned inhibitor, it can be deduced that the more effective site for electrophilic attack is $\mathrm{S}$ atom. Moreover, the planar and simplicity of inhibitor structure lead to enhancing the efficiency of inhibitor adsorption on steel surface by functional groups especially sulfur and this is the main reason for high inhibition efficiencies in very low concentrations. This result is also depicted in Fig. 3.

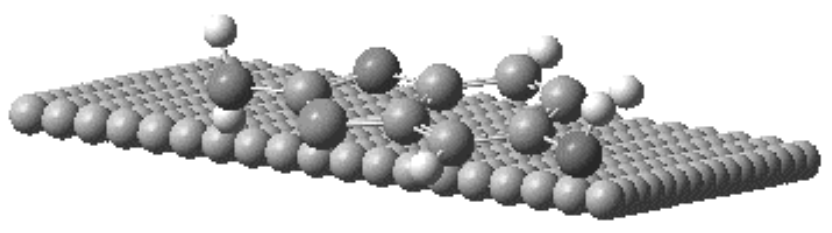

Figure 3. The possibility of the electrophilic attack on surface.

\subsection{Potentiodynamic Polarization Measurements}

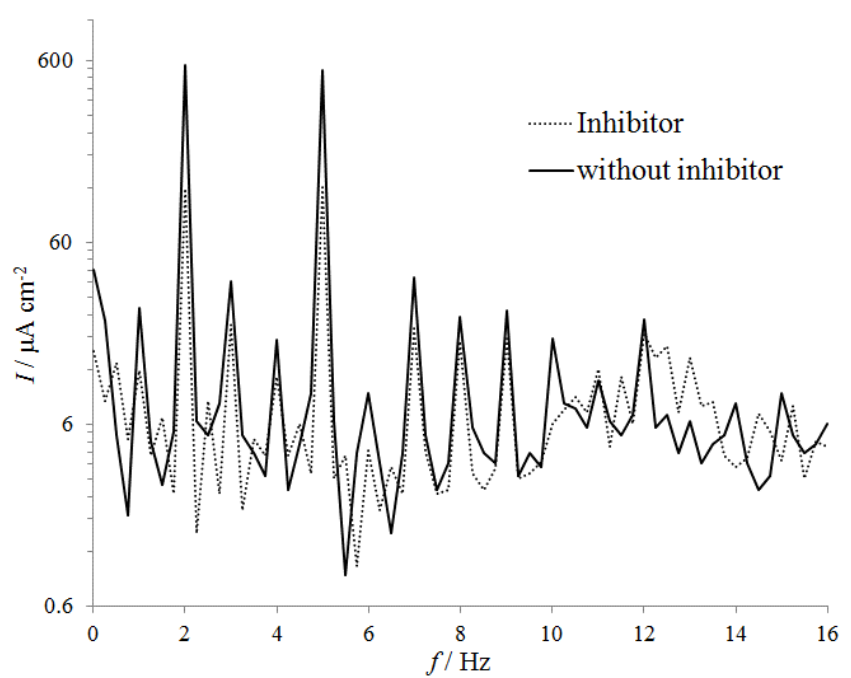

Figure 4. Electrochemical frequency modulation curves of steel in $5 \% \mathrm{HCl}$ (a) without and (b) with $2 \times 10^{-4} \mathrm{M}$ inhibitor.
Fig. 4 indicates the potentiodynamic polarization curves of carbon steel in $5 \%$ $\mathrm{HCl}$ solution in the absence and existence of 2-Amino-6-hydroxybenzothiazole. The corrosion factors extracted from the polarization curves including corrosion potential $\left(E_{\text {corr }}\right)$, polarization resistance $\left(R_{\mathrm{p}}\right)$, cathodic and anodic Tafel slopes $\left(\beta_{\mathrm{a}}\right.$ and $\beta_{\mathrm{c}}$ ), corrosion current density $\left(I_{\text {corr }}\right)$ and the degree of surface coverage $(\theta)$ are presented in Table 3 .

Table 3. Corrosion parameters obtained by EFM for the corrosion of steel X80 in $5 \% \mathrm{HCl}$ solution in absence and presence of different concentrations of thiazole.

\begin{tabular}{|c|c|c|c|c|c|c|c|}
\hline $\begin{array}{c}\text { Concentration } \\
/ \mathbf{M}\end{array}$ & $\begin{array}{c}\boldsymbol{I}_{\text {corr }} \\
/ \boldsymbol{\mu} \mathbf{A ~ \mathbf { ~ m } ^ { - 2 }}\end{array}$ & $\begin{array}{c}\beta_{a} \\
/ \mathbf{m V ~} \mathbf{d e c}^{-\mathbf{1}}\end{array}$ & $\begin{array}{c}-\beta_{c} \\
/ \mathbf{m V} \mathbf{d e c}^{-\mathbf{1}}\end{array}$ & $\begin{array}{c}\boldsymbol{R}_{\boldsymbol{P}} \\
/ \mathbf{\Omega} \mathbf{~ c m}^{-\mathbf{2}}\end{array}$ & $\boldsymbol{I E} \mathbf{\%}$ & $\boldsymbol{C F}(\mathbf{2})$ & $\boldsymbol{C F} \mathbf{( 3 )}$ \\
\hline Blank & 497.22 & 52 & -66 & 25.39 & - & 2.11 & 2.95 \\
\hline $2 \times 10^{-4}$ & 57.51 & 42 & -58 & 183.95 & 88.43 & 1.91 & 274 \\
\hline
\end{tabular}

The surface coverage degree and the inhibition efficacy for diverse levels of inhibitor are computed by the subsequent equation [37, 38]:

$$
I E \%=\frac{I-\dot{I}}{I} \times 100
$$

where $I$ and $\dot{I}$ refer to the corrosion current densities in the absence and presence of corrosion inhibitor, respectively. According to Fig. 4, both anodic and cathodic current densities decrease in the existence of thiazole. The key cathodic reaction in acidic media is the reduction of hydrogen ions to generate hydrogen. This outcome offers that adding inhibitor decreases the anodic reaction and retards the hydrogen progress reaction consequently this compound can be categorized as combined cathodic and anodic type corrosion inhibitors, as displacement of electrode potential is less than $85 \mathrm{mV}[37,38]$. The polarization resistance $\left(R_{\mathrm{p}}\right)$ from the Tafel extrapolation technique was computed by the Stern-Geary Equation [38].

$$
R_{p}=\frac{B}{I_{\text {corr }}}=\frac{\beta_{a} \beta_{c}}{2.303\left(\beta_{a}+\beta_{c}\right) I_{\text {corr }}}
$$

The polarization resistance rises in the existence of inhibitor, demonstrating the inhibitor adsorption on the surface of metal for effective blockage of the active sites and inhibiting corrosion.

\subsection{Electrochemical Frequency Modulation}

The use of electrochemical Frequency Modulation in corrosion inhibition studies is becoming common and has been studied by numerous scientists [1720]. The main advantages of this electrochemical method are that it is a nondestructive with an internal self-check by two causality parameters [21]. The corrosion activity of $\mathrm{X} 80$ steel in $5 \% \mathrm{HCl}$ in the absence and presence of inhibitor are presented in Fig. 5.

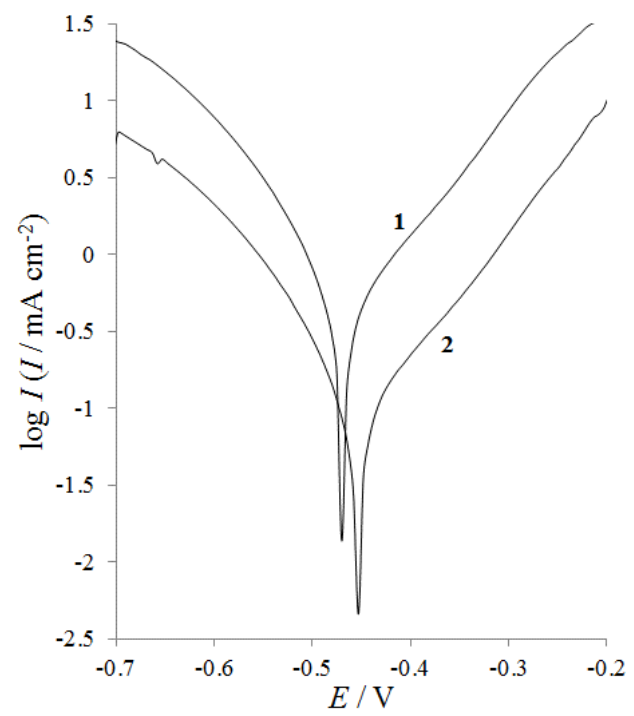

Figure 5. Anodic and cathodic polarization curves of steel in $5 \% \mathrm{HCl}$ (1) without and (2) with $2 \times 10^{-4} \mathrm{M}$ inhibitor. 
Each spectrum demonstrates the current response versus frequency. The harmonic and intermodulation bands are obviously visible with values much more than the background noise and are applied to measure the corrosion parameters [17,21]. The electrochemical factors including the Tafel slopes $\left(\beta_{\mathrm{a}}\right.$ and $\left.\beta_{\mathrm{c}}\right)$, corrosion current density $\left(I_{\text {corr }}\right)$ and the causality factors, CF-2 and CF-3 are calculated from the subsequent equations $[17,21]$ and are presented in Table 4.

$$
\begin{aligned}
& I_{c o r r}=\frac{I_{\omega 1, \omega 2}^{2}}{2 \sqrt{8 I_{\omega 1, \omega 2} I_{2 \omega 2 \pm \omega 1}-3 I_{\omega 2 \pm \omega 1}^{2}}} \\
& \beta_{a}=\frac{I_{\omega 1, \omega 2} U_{0}}{I_{\omega 2 \pm \omega 1}+\sqrt{8 I_{\omega 1, \omega 2} I_{2 \omega 2 \pm \omega 1}-3 I_{\omega 2 \pm \omega 1}^{2}}} \\
& \beta_{c}=\frac{I_{\omega 1, \omega 2} U_{0}}{-I_{\omega 2 \pm \omega 1}+\sqrt{8 I_{\omega 1, \omega 2} I_{2 \omega 2 \pm \omega 1}-3 I_{\omega 2 \pm \omega 1}^{2}}}
\end{aligned}
$$

where $I$ refers to the instantaneous current density at the working electrode determined at frequency $\omega$ and $U_{0}$ is amplitude of the sine wave distortion.

Table 4. Corrosion parameters obtained by potentiodynamic polarization for the corrosion of steel $\mathrm{X} 80$ in $5 \% \mathrm{HCl}$ solution in absence and presence of different concentrations of thiazole.

\begin{tabular}{|c|c|c|c|c|c|c|}
\hline $\begin{array}{c}\text { Concentration } \\
/ \mathbf{M}\end{array}$ & $\begin{array}{c}\boldsymbol{I}_{\text {corr }} \\
/ \boldsymbol{\mu} \mathbf{A ~ c m}\end{array}$ & $\begin{array}{c}-E_{\text {corr }} \\
/ \mathbf{V}\end{array}$ & $\begin{array}{c}\beta_{a} \\
/ \mathbf{m V ~} \mathbf{d e c}^{-\mathbf{1}}\end{array}$ & $\begin{array}{c}-\beta_{c} \\
/ \mathbf{m V ~} \mathbf{d e c}^{-\mathbf{1}}\end{array}$ & $\begin{array}{c}R_{p} \\
/ \mathbf{\Omega} \mathbf{~ c m}^{-\mathbf{2}}\end{array}$ & $\boldsymbol{I E} \%$ \\
\hline Blank & 524.81 & -0.471 & 104 & -72 & 35.27 & - \\
\hline $2 \times 10^{-4}$ & 116.95 & -0.453 & 108 & -91 & 358.44 & 77.71 \\
\hline
\end{tabular}

Table 4 represent that without using inhibitor, the corrosion current density and so corrosion rate is higher representing the vulnerability of the X80 steel to corrosion in the strong acid media. Introducing inhibitor into the corrodent decreases corrosion current density representing that inhibitor reduces the acidinduced corrosion of the X80 pipeline steel. The achieved corrosion factors are in accordance with potentiodynamic polarization factors. Furthermore, based on table, the causality factors $\mathrm{CF}(2)$ and $\mathrm{CF}(3)$ are near to their theoretic values which shows a causal relation between the perturbation signal and so the EFM data are reliable.

\subsection{Electrochemical Impedance Spectroscopy Measurements}

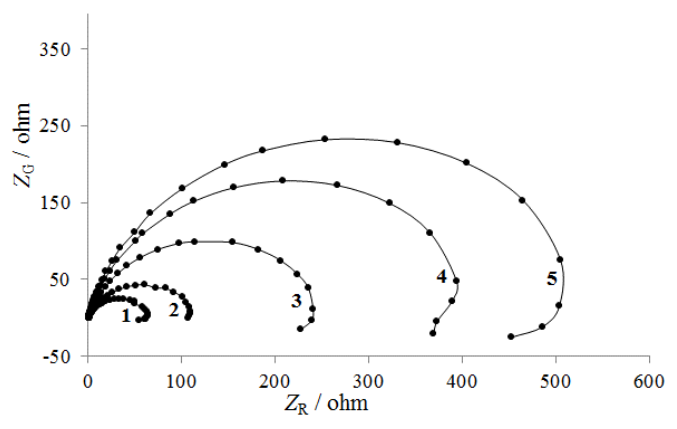

Figure 6. Nyquist plots for steel in $5 \% \mathrm{HCl}$ without and with various concentration of thiazole at $25{ }^{\circ} \mathrm{C}$ : (1) $0,(2) 1 \times 10^{-5}$, (3) $5 \times 10^{-5}$, (4) $1 \times 10^{-4}$, (5) $2 \times 10^{-4} \mathrm{M}$.

Fig. 6 indicates impedance plots obtained for the steel X80 corrosion in 5\% $\mathrm{HCl}$ solution with no and with diverse levels of thiazole attained at $E_{\text {corr }}$. The impedance data indicate one capacitive arc and one inductive arc at highfrequency values and at low-frequency values which shows two time constants, respectively. The existence of the inductive arc in low frequencies may be ascribed to the relaxation procedure achieved using adsorption species such as $\mathrm{H}_{\mathrm{ads}}{ }^{+}$and $\mathrm{Cl}_{\text {ads }}{ }^{-}$on the surface of X80 steel [39-42]. Moreover, it may be ascribed to the passivated surface re-dissolution at low frequency values [42]. In addition, the inductive arc is maybe resulted through stabilizing the layer by the corrosion reaction products on the steel surface like $[\mathrm{FeH}]_{\mathrm{ads}}$ and $[\mathrm{FeOH}]_{\mathrm{ads}}$ containing inhibitor molecules [40]. The high frequencies arc results from the time constant corresponding to steel corrosion and thus related to the electrical double layer and charge transfer resistance.
The inhibited steel impedance enhances by raising the inhibitor's level and accordingly the inhibition efficacy rises. These curves have same shape, which is not changed through all examined levels, representing the corrosion mechanism shows no significant change in the presence of inhibitor. The equivalent circuit well-matched with the impedance diagram obtained in the absence and existence of inhibitor is represented in Fig. 7.

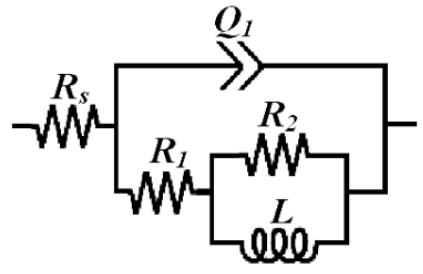

Figure 7. Equivalent circuits compatible with the experimental impedance data in Fig. 2 for corrosion of steel electrode at different inhibitor concentrations.

To achieve a suitable impedance simulation for metal corrosion, it is essential to substitute the capacitor, $C$, with a constant phase element due to the micro and nano roughness on the surface $[43,44]$. The impedance of the constant phase element is expressed as $Z_{C P E}=1 / Q(i w)^{n}$, where $Q$ refers to a capacitive element associated with the mean double layer capacitance $\left(C_{\mathrm{dl}}\right)$, and $n$ refers to a dimensionless factor associated with the constant phase angle. The electrical circuit elements, $R_{\mathrm{s}}, R_{\mathrm{ct}}$ and $C P E_{\mathrm{dl}}$ represent solution resistance, a $C P E$ relating with the charge transfer resistance and double layer capacitance. $L$ and $R_{\mathrm{L}}$ represent the inductive elements associated with the relaxation procedure.

The simplest method needs the theoretical transfer function $Z(\omega)$ to be expressed by:

$$
\begin{aligned}
& Z(\omega)=R_{s}+\frac{R_{c t}}{1+\left(Z_{L}(\omega) / R_{c t}\right)}+\left(i \omega R_{c t} Q_{d l}\right)^{n} \\
& Z_{L}(\omega)=\frac{i \omega R_{L} L}{i \omega L+R_{L}}
\end{aligned}
$$

$\omega$ refers to the frequency in rad/s, $\omega=2 \pi f$ and $f$ represents frequency in $\mathrm{Hz}$. To verify the equivalent circuit, the fitting of empirical data to equivalent circuit are performed and the circuit elements are attained. The inhibition efficiency is calculated by the subsequent equation [37]:

$$
I E \%=\frac{R_{c t}^{-1}-R_{c t(i n h)}^{-1}}{R_{c t}^{-1}} \times 100
$$

Table 5. Impedance spectroscopy data for corrosion of steel in $5 \% \mathrm{HCl}$ solution without and with different concentration of thiazole.

\begin{tabular}{|c|c|c|c|c|c|c|c|}
\hline $\begin{array}{c}\text { Concentration } \\
/ \mathbf{M}\end{array}$ & $\begin{array}{c}\boldsymbol{R}_{\mathbf{S}} \\
/ \mathbf{o h m}\end{array}$ & $\begin{array}{c}\boldsymbol{R}_{\mathbf{c t}} \\
/ \mathbf{o h m}\end{array}$ & $\begin{array}{c}\boldsymbol{Q}_{\mathrm{d} \mathbf{\times}} \times \mathbf{1 0}^{\mathbf{4}} \\
/ \mathbf{F}\end{array}$ & $\boldsymbol{n}$ & $\begin{array}{c}\boldsymbol{R}_{\mathbf{L}} \\
/ \mathbf{o h m}\end{array}$ & $\begin{array}{c}\boldsymbol{L} \\
/ \mathbf{H}\end{array}$ & $\boldsymbol{I E} \mathbf{\%}$ \\
\hline Blank & 1.3 & 58 & 11 & 0.82 & 8 & 11 & - \\
\hline $1 \times 10^{-5}$ & 1.3 & 105 & 12 & 0.81 & 12 & 57 & 44.76 \\
\hline $5 \times 10^{-5}$ & 1.5 & 221 & 9 & 0.85 & 35 & 109 & 73.75 \\
\hline $1 \times 10^{-4}$ & 1.6 & 335 & 6 & 0.87 & 104 & 225 & 82.69 \\
\hline $2 \times 10^{-4}$ & 1.5 & 403 & 4 & 0.88 & 155 & 308 & 85.61 \\
\hline
\end{tabular}

Table 5 shows the equivalent circuit factors for the Nyquist spectra for corrosion of $\mathrm{X} 80$ steel in $5 \% \mathrm{HCl}$ solution. The outcomes reveal that this inhibitor has high inhibition efficiencies in very low concentrations. In addition, the presence of thiazole enhances the value of $R_{c t}$ and decreases $Q_{\mathrm{dl}}$ representing that the exposed area decreases. Moreover, a reduction in $Q_{\mathrm{dl}}$, which can be resulted from a reduction in local dielectric constant and/or a rise in the electrical double layer thickness, offers that the inhibitor adsorbed on metal surface and the creation of a inhibition layer on the surface of electrode [45]. The thickness of this inhibition layer rises with enhance in the amount of inhibitor, as more inhibitor will electrostatically adsorb on the surface of electrode [46].

Since the $Q_{d l}$ exponent $(n)$ refer to a criteria for the heterogeneity of surface, values of $n$ specifies that the surface of steel becomes more and more homogeneous by increasing the amount of inhibitor because of its adsorption on the surface of steel and decreasing corrosion. 


\subsection{Electrochemical noise measurements}

The data of electrochemical noise is considered as the natural random potential and current fluctuations around several average values which occur on the surface of electrode [47]. Therefore, statistical approaches were reported to be mainly suitable for analyzing electrochemical noise data in the time domain [48]. This statistical study involves the approximation of the electrochemical noise resistance. The noise resistance $\left(R_{\mathrm{n}}\right)$ achieved via the standard deviation of potential and the standard deviation of current $\left(R_{\mathrm{n}}=\sigma_{\mathrm{V}} / \sigma_{\mathrm{I}}\right)$, which were calculated using the following equations [49].

$$
\begin{array}{ll}
\sigma_{V}=\sqrt[2]{\frac{\sum_{i=1}^{n}\left(V_{i}-M_{V}\right)^{2}}{n}} & M_{V}=\frac{\sum_{i=1}^{n} V_{i}}{n} \\
\sigma_{I}=\sqrt[2]{\frac{\sum_{i=1}^{n}\left(I_{i}-M_{I}\right)^{2}}{n}} & M_{I}=\frac{\sum_{i=1}^{n} I_{i}}{n}
\end{array}
$$

where $\sigma_{\mathrm{V}}$ is the standard deviation of potential noise,,$\sigma_{\mathrm{I}}$ is the standard deviation of current noise and $n$ refer to total number of measurements. It is observed that the electrochemical noise data are taken into account containing drift or direct current (DC) trend, which might be expressed as a alteration of the average potential or current divided with time, i.e. $\left(\bar{E}_{2}-\bar{E}_{1}\right) /\left(t_{2}-t_{1}\right)$ or $\left(\bar{I}_{2}-\bar{I}_{1}\right) /\left(t_{2}-t_{1}\right)$ [50]. It is believed that this drift could affect the statistical result [51].

a)

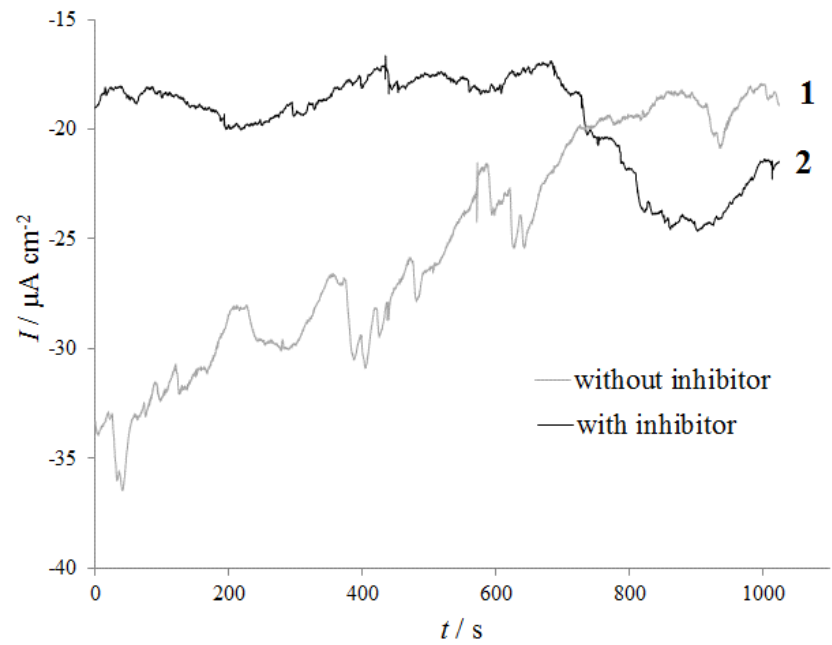

b)
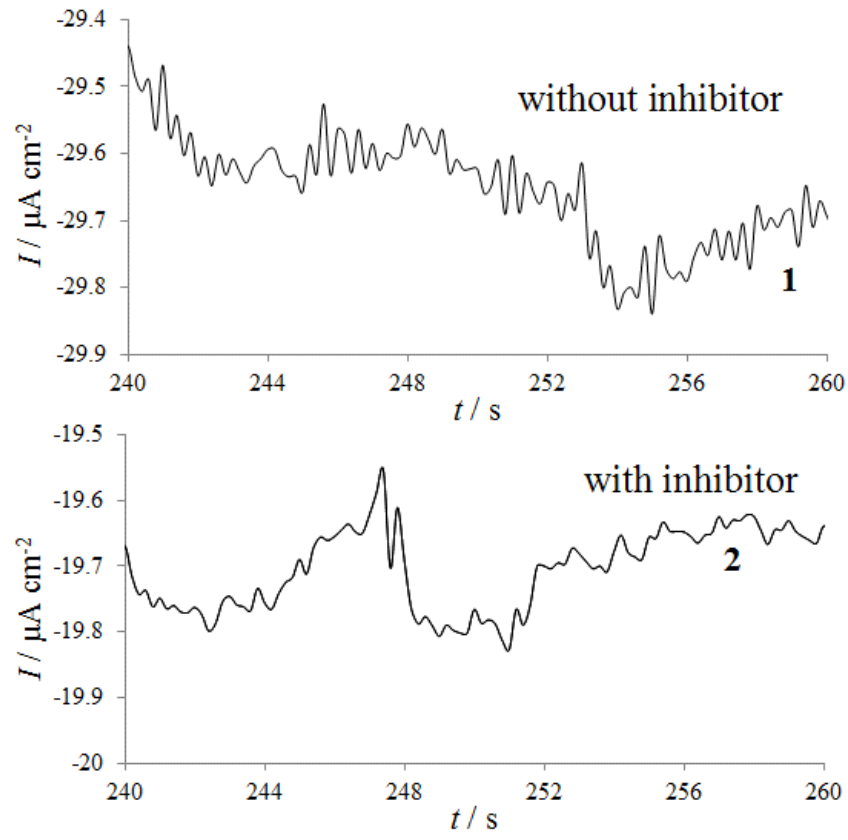

Figure 8. (a) Current noise data and (b) transient amplitude for carbon steel in $5 \% \mathrm{HCl}$ solution: 1) without and 2) with $0.0002 \mathrm{M}$ of thiazole.
Fig. 8 depicts the current time data of the samples immersed in $5 \% \mathrm{HCl}$ solution and with $0.0002 \mathrm{M}$ of thiazole. The series of current noise time without the inhibitor indicates higher amplitude transients and the transients in the existence of the inhibitors are insignificant (Fig. 8b) which can be a superficial sign of efficiency of the inhibitor. Moreover, a critical step is essential to efficiently eliminate DC trend from experimental noise data, which can largely influence on the result of the data analysis [47]. However, there are, different ways to eliminate DC trends, such as polynomial fitting and wavelet analysis. Among different DC trend removal methods, polynomial fitting is used in this work which consists of fitting a polynomial of a given order to the current and potential noise time and next, subtracting the calculated curve so as to maintain the residuals. Polynomial detrending of electrochemical noise data with order $m$ should be as subsequent [51, 52]:

$$
x_{m}(t)=x(t)-f_{m}(t)
$$

where $x(t)$ refers to raw EN time record and $f_{\mathrm{m}}(\mathrm{t})$ represents polynomial fitting function. In addition, $x_{\mathrm{m}}(\mathrm{t})$ is the residual corresponding to the polynomial fitting with the $m$ order.
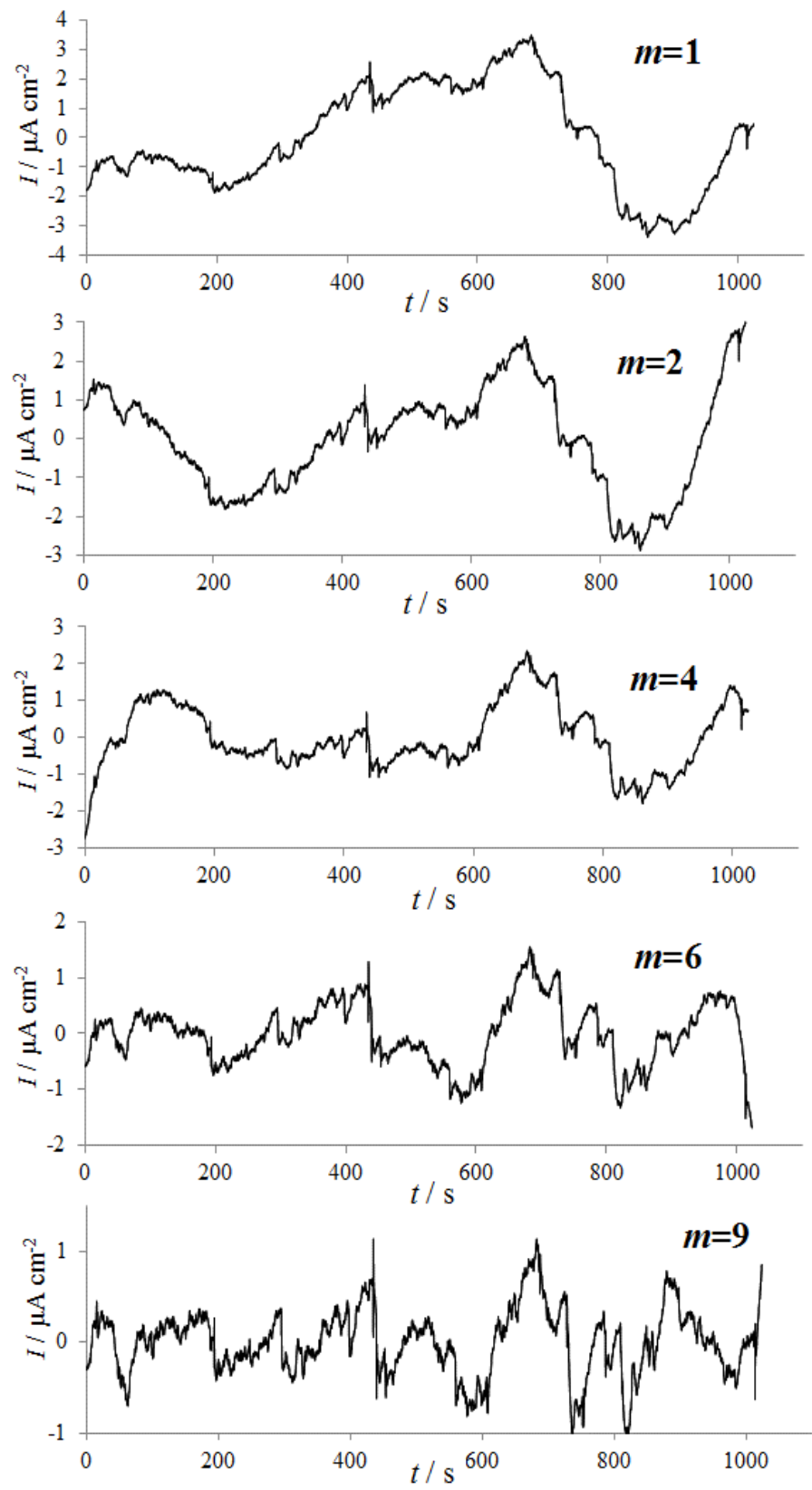

Figure 9. The detrended current noise time series for steel in $5 \% \mathrm{HCl}$ within the presence of $0.002 \mathrm{M}$ of thiazole with different $m$ orders polynomial fitting. 
Fig. 9 indicates the detrended current noise time series for X80 steel in different $m$ orders of polynomial fitting with $0.0002 \mathrm{M}$ inhibitor. As can be seen, the detrended EN time fluctuates around zero and their average value is very low, and the overall drifts are removed. A slight dependency of the shape, amplitude and the width of individual transients on the value of $m$ are obtained from the figure. As can be seen, some relatively trends still exist in $m=1$, which still cause the transients show unclearly. Comparing to $m=1$, following elimination of drift by $m=4$, the transients become more obvious and several long period fluctuations reduce, which is ascribed to the elimination of the low frequency signals. This type of long period fluctuations is frequently taken into account as the low frequency trend and should be eliminated fully. In the very high order of drift removal, more useful low frequency signals is eliminated which is related to the over elimination of these signals [50]. Actually, these fluctuations has much shorter period comparing to the measurement period $t$ and thus should not be taken into account as the low frequency trend. Consequently, the very high order of polynomial fitting is unsuitable for the drift removal and elimination process perhaps just requires removing the general drift in the noise time records [50].

Table 6. Statistical parameters of the ECN raw data without and with $0.002 \mathrm{M}$ thiazole before and after trend removal by different order $(m=1-9)$.

\begin{tabular}{|c|c|c|c|c|c|c|c|}
\hline Conc. / M & $\boldsymbol{m}$ & $\boldsymbol{I}_{\mathbf{r m s}}$ & $\begin{array}{c}\overline{\boldsymbol{I}} \\
\boldsymbol{\mu} \mathbf{A}\end{array}$ & $\boldsymbol{\sigma}_{\mathbf{I}}$ & $\begin{array}{c}\overline{\boldsymbol{E}} \\
\boldsymbol{\mu} \mathbf{\boldsymbol { V }}\end{array}$ & $\boldsymbol{\sigma}_{\mathbf{V}}$ & $\begin{array}{c}\boldsymbol{R}_{\mathbf{n}} \\
/ \mathbf{\Omega}\end{array}$ \\
\hline blank & Raw data & 25.83 & -25.32 & 5.11 & -511434 & 395.6162 & 77.42 \\
\hline & 1 & 1.25 & $1.41 \times 10^{-16}$ & 1.25 & $-1.22 \times 10^{-6}$ & 126.675 & 101.34 \\
\hline & 2 & 1.21 & $-2.68 \times 10^{-6}$ & 1.21 & $3.67 \times 10^{-7}$ & 115.4098 & 95.38 \\
\hline & 3 & 1.19 & $4.88 \times 10^{-6}$ & 1.19 & $-5.91 \times 10^{-7}$ & 88.2147 & 74.13 \\
\hline & 4 & 1.08 & $7.13 \times 10^{-6}$ & 1.08 & $3.17 \times 10^{-6}$ & 94.4784 & 87.48 \\
\hline & 5 & 1.02 & $5.86 \times 10^{-7}$ & 1.02 & $-3.92 \times 10^{-7}$ & 83.5074 & 81.87 \\
\hline & 6 & 0.97 & $-4.11 \times 10^{-7}$ & 0.97 & $-4.97 \times 10^{-7}$ & 120.5128 & 124.24 \\
\hline & 7 & 0.96 & $1.95 \times 10^{-6}$ & 0.96 & $7.03 \times 10^{-6}$ & 104.0736 & 108.41 \\
\hline & 8 & 0.94 & $5.22 \times 10^{-6}$ & 0.94 & $-8.46 \times 10^{-7}$ & 103.1744 & 109.76 \\
\hline & 9 & 0.93 & $1.95 \times 10^{-6}$ & 0.93 & $6.45 \times 10^{-6}$ & 136.1055 & 146.35 \\
\hline & & & & & & & \\
\hline 0.0002 & Raw data & 19.69 & -19.57 & 2.21 & -531667 & 1658.89 & 750.63 \\
\hline & 1 & 1.75 & $3.91 \times 10^{-6}$ & 1.75 & $-4.01 \times 10^{-14}$ & 1534.66 & 876.95 \\
\hline & 2 & 1.33 & $3.13 \times 10^{-6}$ & 1.33 & $-2.02 \times 10^{-6}$ & 880.81 & 662.26 \\
\hline & 3 & 1.31 & $3.91 \times 10^{-6}$ & 1.31 & $-3.94 \times 10^{-6}$ & 944.98 & 721.36 \\
\hline & 4 & 0.89 & $-2.52 \times 10^{-6}$ & 0.89 & $-5.92 \times 10^{-6}$ & 612.86 & 688.61 \\
\hline & 5 & 0.59 & $-9.81 \times 10^{-7}$ & 0.59 & $-1.23 \times 10^{-6}$ & 339.39 & 575.24 \\
\hline & 6 & 0.55 & $7.81 \times 10^{-7}$ & 0.55 & $-3.33 \times 10^{-6}$ & 227.31 & 413.29 \\
\hline & 7 & 0.55 & $-1.42 \times 10^{-6}$ & 0.55 & $9.77 \times 10^{-7}$ & 213.46 & 388.11 \\
\hline & 8 & 0.43 & $-4.49 \times 10^{-6}$ & 0.43 & $-6.63 \times 10^{-6}$ & 183.90 & 427.68 \\
\hline & 9 & 0.36 & $-2.29 \times 10^{-6}$ & 0.36 & $-6.79 \times 10^{-6}$ & 177.71 & 493.65 \\
\hline
\end{tabular}

Table 6 illustrates the statistical factors of the EN data without and with 0.0002 $\mathrm{M}$ thiazole before and after trend removal by different order $(m=1-9)$ containing standard deviation $\left(\sigma_{\mathrm{V}}\right.$ and $\left.\sigma_{\mathrm{I}}\right)$, the potential and current average value $(\bar{E}$ and $\bar{I})$, root mean square of current $\left(I_{\mathrm{rms}}\right)$ and noise resistance $\left(R_{\mathrm{n}}\right)$. According to Table, with increasing $m, \bar{I}$ and $\bar{E}$ decrease approximately $10^{8}-10^{18}$ times following drift elimination and become nearly equal to zero, thus the influences of $m$ on them could be unnoticed in very high $m$. In this case, according to $I_{r m s}{ }^{2}=\vec{I}^{2}+\sigma_{1}^{2}, \sigma_{\mathrm{I}}$ should be closely equal to $I_{\mathrm{rms}}$ following detrending. $\sigma_{\mathrm{E}}, \sigma_{\mathrm{I}}$ and $I_{\mathrm{rms}}$ slightly decrease in $m \geq 6$ thus the polynomial fitting looks to be better with moderate $m$. Though, the values of $m<6$ would be suggested to prevent large computed errors and great fluctuations at the start and the end of the data. $R_{\mathrm{n}}$ displays very irregular variations following drift elimination with enhancing $m$. Based on the definition of $R_{\mathrm{n}}$, its value will be defined using $\sigma_{\mathrm{E}}$ and $\sigma_{\mathrm{I}}$, so its alteration following drift elimination would be indefinite. These results demonstrate that one main point of this technique is selecting a proper order. So $R_{\mathrm{n}}$ can be utilized to investigate the influence of order on analysis of the electrochemical noise time records [31,53]. The effect of order on the $R_{\mathrm{n}}$ at different inhibitor concentrations is shown in Table 7. It is obvious that in the case of time series with no DC trend elimination, in spite of the fact that all inhibited specimens indicate inhibition behavior, no obvious trend is found for noise resistance. These findings prove the necessity for DC trend elimination prior applying additional noise analysis. Pre-treating time series with $m=1,2$ can also identify no continuous growing trend for $R_{\mathrm{n}}$. So, choosing low orders could cause the noise data misinterpretation. When $m$ is equal to 3,4 and 5, suitable trend relationship is found between $R_{\mathrm{n}}$ and charge transfer and polarization resistance obtained by EIS and polarization measurements, respectively. In spite of the trend relation, it is notable that the degree of $R_{\mathrm{n}}$ differs from the relating resistance obtained from other methods. The major reason for this is the difference between experimental conditions of these techniques used to assess corrosion resistance of X80 steel in acid solution. Contrasting DC polarization and EIS, applying external perturbation is not needed in EN measurements. Actually, data can be achieved from the natural fluctuations corresponding to potential and current at corrosion potential. This causes the least interference with the system resulting in a more exact data assessment than other electrochemical methods [54]. According to Table 7, with enhancing order of the polynomial $m>5$ causes more trend elimination and no continuous increasing manner for $R_{\mathrm{n}}$, via it is probable that this is accompanied by increasing loss of valuable data [55].

Table 7. Effect of order $m$ of polynomial method on $R_{\mathrm{n}}$ in different thiazole concentrations.

\begin{tabular}{|c|c|c|c|c|c|c|c|c|c|c|c|}
\hline \multicolumn{10}{|c|}{$\boldsymbol{~} \Omega$} & \multicolumn{10}{|c|}{$\boldsymbol{I E} \boldsymbol{\%}$} \\
\hline & $\boldsymbol{m = 0}$ & $\boldsymbol{m = 1}$ & $\boldsymbol{m = 2}$ & $\boldsymbol{m}=\mathbf{3}$ & $\boldsymbol{m = 4}$ & $\boldsymbol{m = 5}$ & $\boldsymbol{m = 6}$ & $\boldsymbol{m = 7}$ & $\boldsymbol{m = 8}$ & $\boldsymbol{m = 9}$ & $\boldsymbol{m = 5}$ \\
\hline blank & 77.42 & 101.34 & 95.38 & 74.13 & 87.48 & 81.87 & 124.24 & 108.41 & 109.76 & 146.35 & - \\
\hline 0.00001 & 149.05 & 248.66 & 349.27 & 205.66 & 169.85 & 134.79 & 286.37 & 550.18 & 138.20 & 310.06 & 48.50 \\
\hline 0.00005 & 177.64 & 277.24 & 215.02 & 289.88 & 268.57 & 231.76 & 344.48 & 307.99 & 376.09 & 328.37 & 67.43 \\
\hline 0.0001 & 759.76 & 567.12 & 479.19 & 477.28 & 452.59 & 419.66 & 312.66 & 771.06 & 764.07 & 768.09 & 80.67 \\
\hline 0.0002 & 750.63 & 876.95 & 662.26 & 721.36 & 688.61 & 575.24 & 413.29 & 388.11 & 427.68 & 493.65 & 87.30 \\
\hline
\end{tabular}

a)
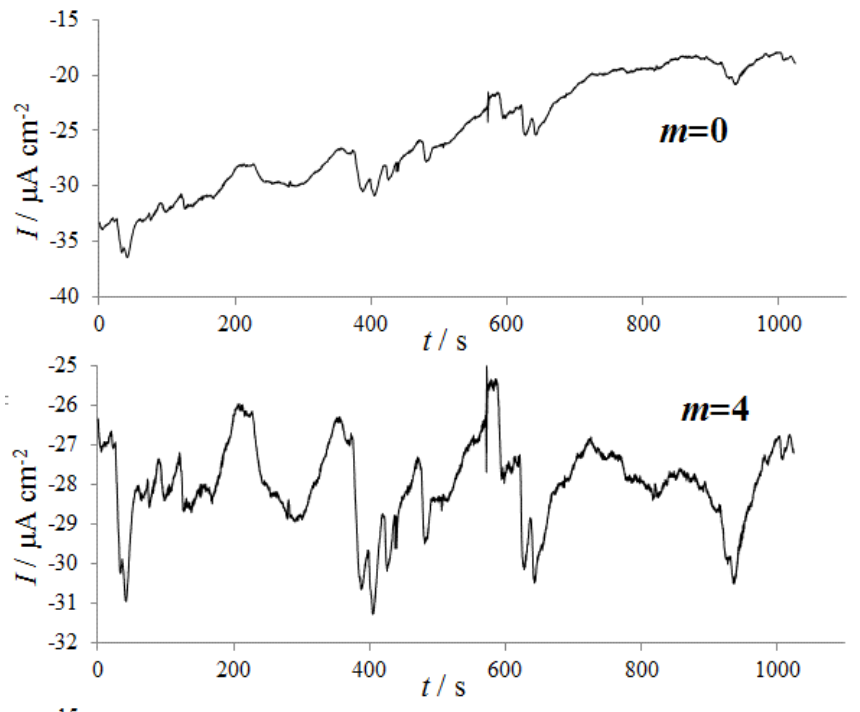

b)
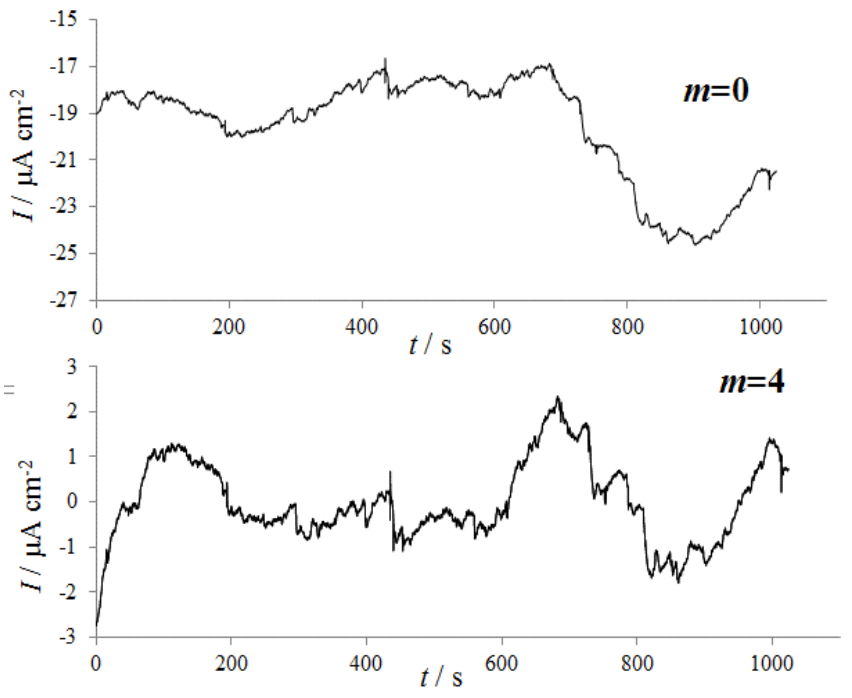

Figure 10. Raw and trend removed current noise data with $m=4$ for steel in 5\% $\mathrm{HCl}$ in the absence (a) and the presence of $0.0002 \mathrm{M}$ thiazole (b).

Fig. 10 indicates the current noise data resulted from the steel in $5 \% \mathrm{HCl}$ both in the absence and existence of thiazole in $m=4$. As seen, noise current fluctuates around zero in the absence and existence of inhibitor without omission of effective corrosion noise. In addition, the current declines in the existence of 
thiazole without and with trends removal. $R_{\mathrm{n}}$ is a suitable factor signifying valuable information on the inhibition impacts of the materials. According to Table 7, the noise resistance of steel electrode in $5 \% \mathrm{HCl}$ solution considerably increases with enhancing inhibitor amounts. The increase in $R_{\mathrm{n}}$ can be directly related to the decrease of $\sigma_{\mathrm{I}}$ because of inhibitor film formation. These outcomes again indicate that the electrochemical noise measurement is a very effective technique for monitoring the metals corrosion. The inhibition performance values were computed from $\mathrm{EN}$ measurements with the following equation:

$$
\% \eta=\frac{R_{n}-R_{n}^{o}}{R_{n}} \times 100
$$

where $R_{\mathrm{n}}$ and $R_{\mathrm{n}}^{\mathrm{o}}$ are the noise resistance in the existence and absence of inhibitor, respectively. Table 8 shows alteration of corrosion inhibition efficacy versus amount of inhibitor.

Table 8. Variation of $q$ and $Z_{n f \rightarrow 0}$ versus thiazole concentrations.

\begin{tabular}{|c|c|c|c|c|c|}
\hline Con. $/ \mathbf{M}$ & Blank & 0.00001 & 0.00005 & 0.0001 & 0.0002 \\
\hline $\boldsymbol{q} / \mathbf{C}$ & $8.93 \times 10^{-3}$ & $7.66 \times 10^{-3}$ & $3.17 \times 10^{-3}$ & $9.59 \times 10^{-4}$ & $5.49 \times 10^{-4}$ \\
\hline $\boldsymbol{Z}_{\boldsymbol{n} \boldsymbol{f} \rightarrow \boldsymbol{0}} / \mathbf{\Omega}$ & 93.28 & 199.74 & 311.47 & 615.76 & 794.38 \\
\hline
\end{tabular}

It is clear that the inhibition performances and trend correlation achieved from noise resistance agree with those obtained from EIS. The inhibition performance values achieved from EIS and EN measurements indicates that the inhibition is more pronounced with increasing inhibitors concentration, indicating that more inhibitor molecule are absorbed on the surface of metal, so providing larger surface coverage and the material acts as adsorbent. In addition, more accurate data for inhibition efficiencies are obtained by electrochemical noise method due to the absence of external applied potential. The applied sinusoidal potential for EIS and EFM is very low and therefore the data obtained by these techniques show more agreement with EN than polarization. The applied cathodic and anodic overpotential in potentiodynamic polarization are high and therefore the obtained inhibition efficiency by this method needs to check its reliability.

\subsection{Power spectral density analysis}

The spectral analysis technique is usually applied to indicate noise signals as power spectral density in the frequency domain. This analysis is a secondary method for interpreting EN data. To carry out spectral analysis, the signal of time domain should be firstly changed to the frequency domain with fast Fourier transform (FFT) [56,57]. Usual PSD $(I)$ plots of the samples in 5\% $\mathrm{HCl}$ solutions with different amounts of inhibitor are presented in Fig. 11.

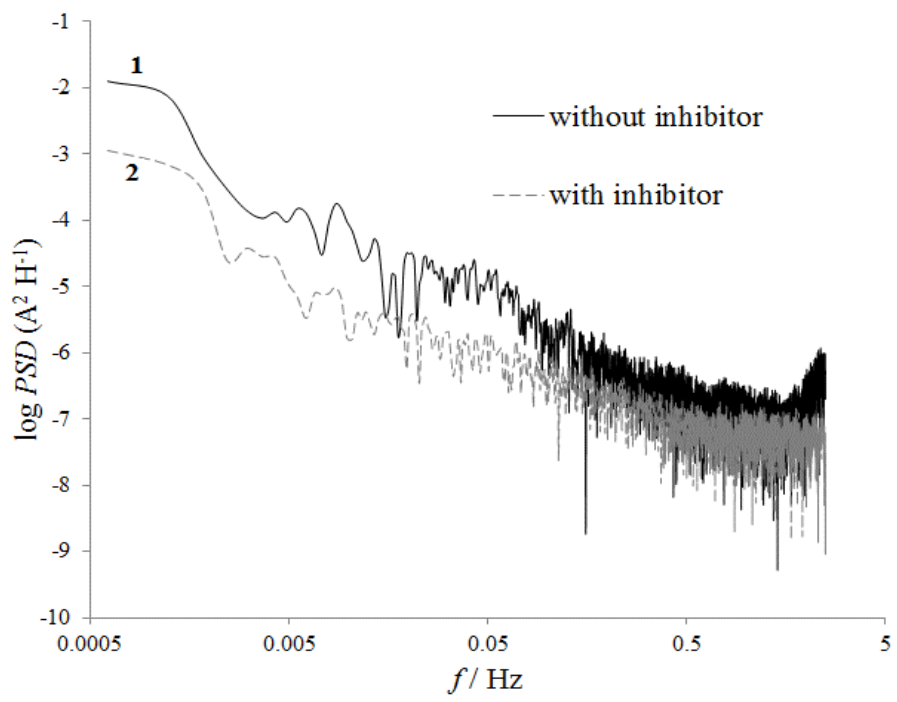

Figure 11. PSD (I) plots of the specimens in $5 \% \mathrm{HCl}$ solutions in the absence (1) and presence of $0.0002 \mathrm{M}$ thiazole (2).

Without using the inhibitors, the PSD $(I)$ plot either in the frequency dependent area or in the white noise area is higher comparing with those in the existence of thiazole.
As a criterion, for total current energy corresponding to signal, spectral analysis indicate that the current value for corrosion reaction passed throughout the system is higher for uninhibited solution. This means the presence of inhibitor in the corrosive solution may hinder the steel corrosion due to the inhibitor adsorption on steel surface [47].

Based on shot noise theory, the charge of all electrochemical events, $q$, could be used to study and analysis of the electrochemical noise data in the frequency domain. Shot noise is created as a result of carrying the current by discrete charge carriers and then the amount of charge carriers passing a specified point will be a random variable. The shot noise is possible to be analyzed for the individual events since they are independent of each other such as the stochastic procedures. The charge corresponding to each electrochemical event $q$ can be achieved from the signals of potential and current noise, with the subsequent equation [58]:

$$
q=\frac{\sqrt{P S D_{I}} \sqrt{P S D_{E}}}{B}
$$

where $B$ is the Stern-Geary coefficient. It is obtained from Eq. (22) that the amplitude of $\operatorname{PSD}(I)$ and $\operatorname{PSD}(E)$ should be considered for getting a suitable characteristic charge.

The corresponding $q$ values in different concentrations of the inhibitors are presented in Table 8. As observed, by enhancing the amount of inhibitor, the $q$ values show a descending trend. The inhibitor reduces rate of metal oxidation in $\mathrm{HCl}$ solution causing a decrease in characteristic charge on the surface of metal. The adsorbing inhibitors on the surface of metal can reduce the characteristic charge [56].

The noise impedance can be derived from $P S D_{\mathrm{E}}$ and $P S D_{\mathrm{I}}$ according to the equation [59]:

$$
Z_{n}=\sqrt{\frac{P S D_{E}}{P S D_{I}}}
$$

and $Z_{n f \rightarrow 0}$, the limit of $Z_{n}$ as the frequency tends to zero, is estimated to the comparable with $R_{\mathrm{p}}$.

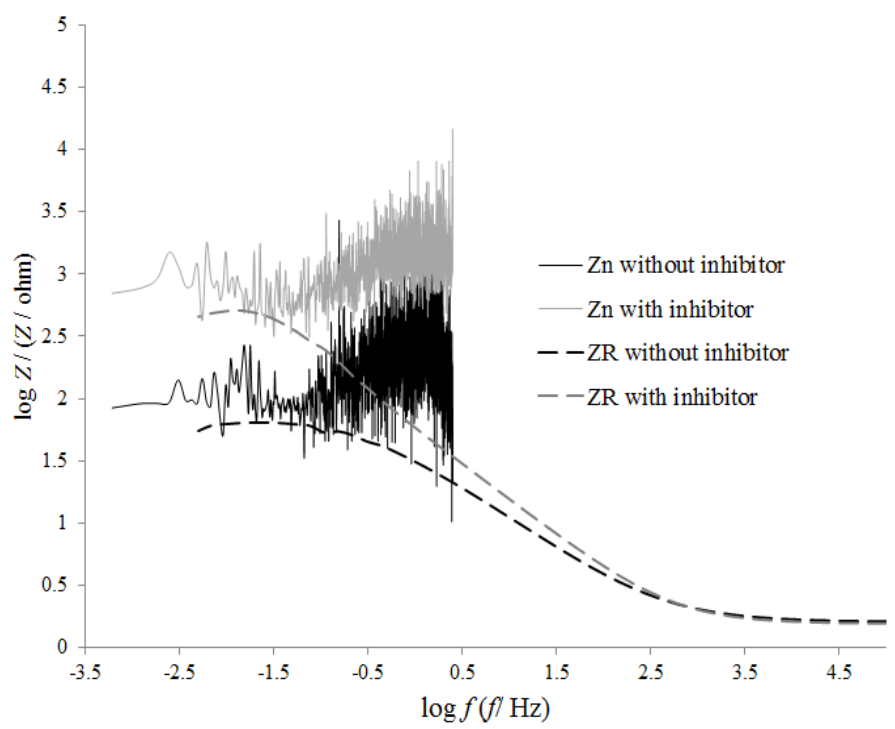

Figure 12. Bode plotes $\left(Z_{R}\right)$ and spectral noise impedance $\left(Z_{\mathrm{n}}\right)$ comparison for carbon steel in $5 \% \mathrm{HCl}$ in the absence and presence of $0.0002 \mathrm{M}$ thiazole.

Fig. 12 shows a comparison between the Bode impedance diagram and noise resistance of steel exposed to $\mathrm{HCl}$ containing different concentrations of inhibitor. Moreover the obtained noise resistance is presented in Table 8. Noise resistance increases with enhancing amount of inhibitor, which indicates the applicability of thiazole in corrosion inhibition. From the figure, there is good trend agreement between impedance and noise resistance in the low frequencies. But, there is no complete agreement between the spectral noise plots and Bode plots which is due to the more accurate data obtained by electrochemical noise. 


\subsection{Adsorption isotherm}

Adsorption isotherms offer data corresponding to the interaction of the adsorbed molecules with the surface [60]. The efficacy of thiazole molecules as an effective corrosion inhibitor is mostly affected by their adsorption ability on the metal surface. The adsorption procedure contains replacing water molecules at metal surface based on the subsequent procedure:

$$
\mathrm{In}_{(\text {sol })}+n \mathrm{H}_{2} \mathrm{O}_{(\text {ads })} \rightarrow \mathrm{In}_{(\text {ads })}+n \mathrm{H}_{2} \mathrm{O}_{(\text {sol })}
$$

where $\operatorname{In}_{(\mathrm{sol})}$ and $\operatorname{In}_{(\mathrm{ads})}$ represent the free solved inhibitor molecules and adsorbed on the surface of metal, respectively, and n refers to the amount of $\mathrm{H}_{2} \mathrm{O}$ molecules substituted with the inhibitor molecules. It is needed to know the adsorption isotherm and the mode of adsorption that can provide critical data on the interaction between inhibitor with the surface of metal.

Different isotherms of adsorption were fitted to the empirical data and then linear regression coefficient values of $\left(\mathrm{R}^{2}\right)$ were obtained from the curves. Based on these outcomes, it can be found that the best explanation for the adsorption mechanism of thiazole can be described by Langmuir isotherm. This isotherm can be presented as follows [61,62]:

$$
\frac{C}{\theta}=\frac{1}{K_{a d s}}+C
$$

where $\theta$ represents the surface coverage, $\mathrm{C}$ is the concentration of inhibitor and $K_{\text {ads }}$ is the adsorption equilibrium constant relating with the standard adsorption free energy.

The linear relationships corresponding to $C / \theta$ versus $C$ obtained from EIS and EN data represented in Fig. 13, propose that adsorbing inhibitor on steel surface obeyed the Langmuir isotherm.

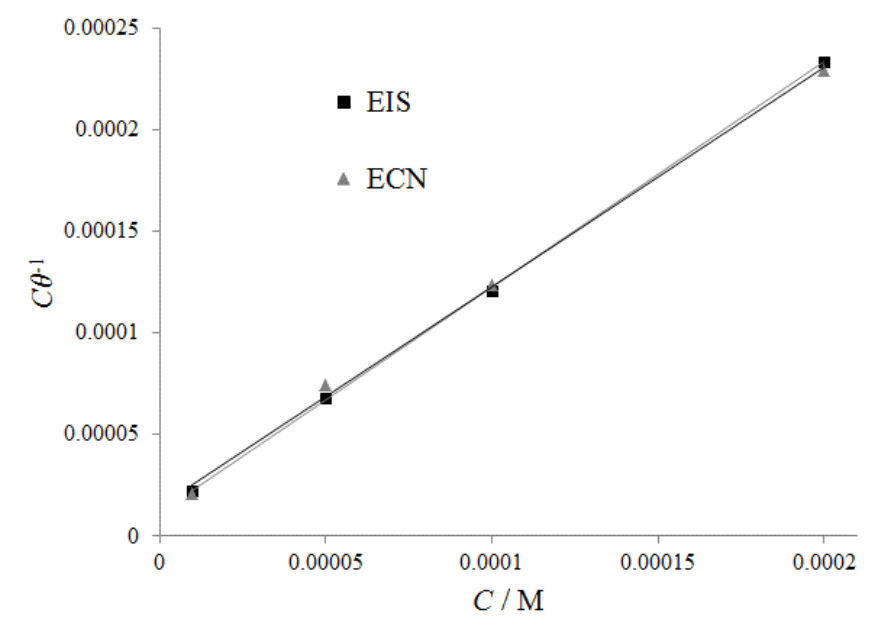

Figure 13. Langmuir isotherm for adsorption of inhibitor on the steel surface according to ECN and EIS data.

The interaction of the molecules of inhibitor with the metal surface could be analyzed by the Gibbs free energy value resulting from the subsequent equation [63]:

$$
\Delta G_{a d s}=-R T \ln \left(55.5 K_{a d s}\right)
$$

where 55.5 is the molar concentration of water in the solution described in M $\left(m o l 1^{-1}\right)$. The calculated values obtained by different electrochemical measurements were presented in Table 9.

Table 9. The values of $K_{\text {ads }}$ and $\Delta G_{\text {ads }}$ corresponding to EIS and ECN data for thiazole adsorption in $\mathrm{HCl}$ solution.

\begin{tabular}{|c|c|c|}
\hline Method & EIS & EN \\
\hline$K_{\text {ads }} / 1 \mathrm{~mol}^{-1}$ & $9.1 \times 10^{3}$ & $6.6 \times 10^{3}$ \\
\hline$\Delta G_{\text {ads }} / \mathrm{kJ} \mathrm{mol}^{-1}$ & -32.53 & -31.75 \\
\hline
\end{tabular}

The $\Delta G_{\text {ads }}$ values obtained from the diverse approaches are in good accordance with each other. The sign of $\Delta G_{\text {ads }}$ values are negative which suggest the spontaneous adsorption of thiazole on the surface of steel. In general, the $-\Delta G_{\text {ads }}$ values close to or less than $20 \mathrm{~kJ} \mathrm{~mol}^{-1}$ are related with the electrostatic interaction of the charged surface of metal with the charged inhibitor molecules (physisorption); however those close to or more than $40 \mathrm{~kJ} \mathrm{~mol}^{-1}$ specify sharing or transfer of charge from the molecules of inhibitor to the surface of metal for formation of a coordinate kind of metal bond (chemisorption) [64]. The values of $\Delta G_{\text {ads }}$ are close to $-30 \mathrm{~kJ} \mathrm{~mol}^{-1}$, which specifies that thiazole absorption on the surface of X80 steel relates to both chemisorption and physisorption.

\subsection{Atomic force microscopy}

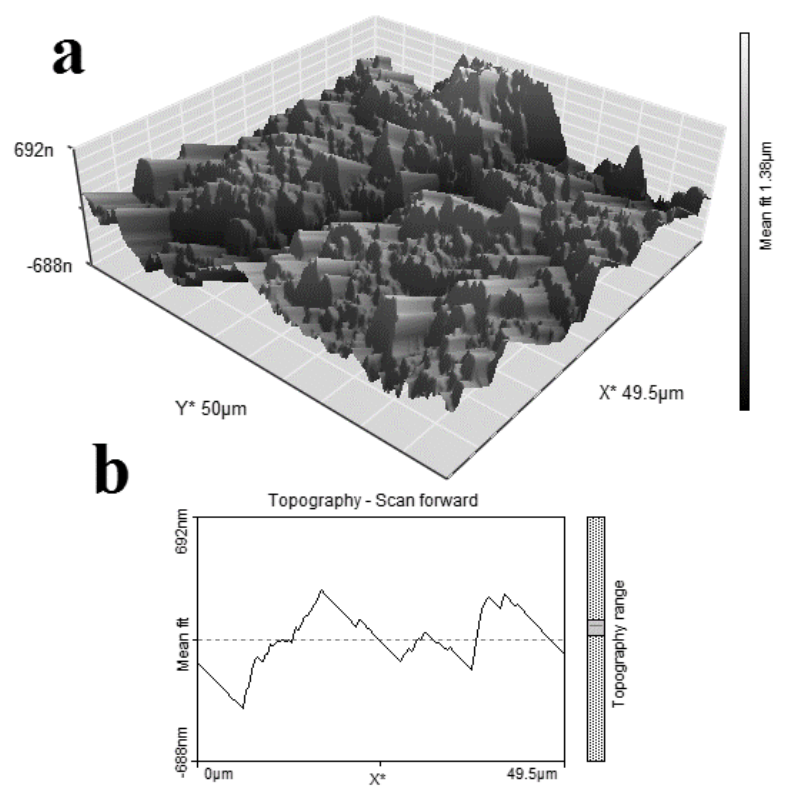

Figure 14. (a) 3D image of atomic force microscopy and (b) height profile graph of steel surface after immersion in $5 \% \mathrm{HCl}$ solution.

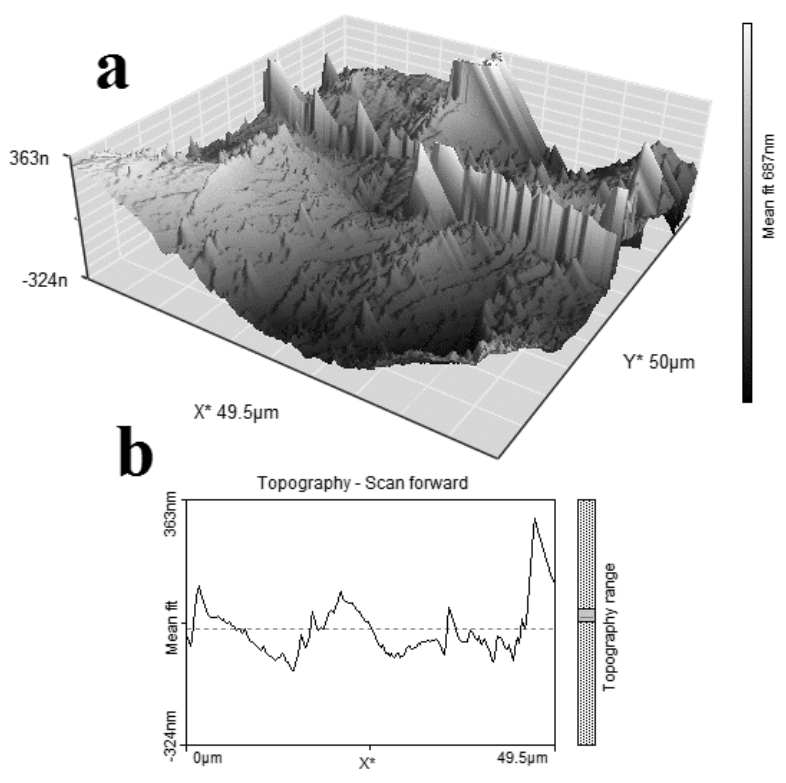

Figure 15. 3D image of atomic force microscopy and (b) height profile graph of steel surface after immersion in $5 \% \mathrm{HCl}$ solution containing $0.002 \mathrm{M}$ thiazole.

More studies performed on the compound corrosion inhibition ability using AFM for characterizing the surface microstructure. Fig. 14\&15 depicts three dimensional AFM images corresponding to the surface of steel following $8 \mathrm{~h}$ exposure in uninhibited and inhibited system at $25^{\circ} \mathrm{C}$. In uninhibited system, the steel surface is very rough and damaged because of dissolving in corrosive media 
(Fig. 14a). In the existence of inhibitor (Fig. 15a), the surface appears smoother which is because of the creation of a compact protective film of inhibitor on the surface of metal, thereby inhibiting the corrosion of steel. Average roughness factor (Ra) was obtained from the respective images for quantifying the roughness of surface. The computed values of Ra show that the roughness of the metal surface submerged in $5 \% \mathrm{HCl}$ is $1.38 \mu \mathrm{m}$. However, addition of inhibitor decreases the Ra to $591 \mathrm{~nm}$.

These outcomes are further supported with height profile graphs (Figs. $14 \mathrm{~b} \& 15 \mathrm{~b})$. The high heterogeneity was found for the sample submerged in 5\% $\mathrm{HCl}$ with no inhibitor, which is shown using rough height profile graph in Fig. 14b. Comparing to the sample in $\mathrm{HCl}$, the height profile graph is smoother in Fig. 15b for inhibitor. This is in good accordance with the outcome achieved from the EIS analysis that the exponent $n$ of the double layer capacitance enhances in the existence of inhibitor in solution.

\section{CONCLUSION}

The 2-Amino-6-hydroxybenzothiazole was studied as a corrosion inhibitor for steel electrode in $5 \% \mathrm{HCl}$ solution with different concentrations by EIS, EFM, potentiodynamic polarization and electrochemical noise methods. The subsequent points can be highlighted:

- Quantum chemical study at the B3LYP/6-31G (d p) basis set level was done to find out the correlation between molecular structure and inhibition ability. Theoretical calculations suggest that the HOMO densities are located around the benzene ring.

- The planar and simplicity of inhibitor structure cause to enhancing the efficiency of adsorption by functional groups especially sulfur and this is the main reason for high inhibition efficiencies in very low concentrations.

- Electrochemical frequency modulation and potentiodynamic polarization showed that thiazole compound had an effective inhibition in very low concentrations for the steel corrosion in $5 \% \mathrm{HCl}$ solution.

- Noise resistance and inhibition performance obtained from EN measurement was in good trend accordance with other approaches.

- It is observed that the polynomial detrending was significantly affected by choosing order. Taking High Order of $m$ may lead to over filtering. Also, for low $m$, the drift could be observed.

- In the case of $m=4$, a good trend relation was found between $R_{\mathrm{n}}$ and the resistances achieved from EIS.

- Power spectral density analysis indicated that the noise impedance and the charge of corrosion procedure decreased in the existence of inhibitor and the noise impedance was in agreement with electrochemical impedance.

- Outcomes achieved from EIS and EN measurements showed that the adsorption of thiazole on steel in 5\% $\mathrm{HCl}$ followed the Langmuir isotherm.

- The values of $\Delta G_{\text {ads }}$ showed that the adsorption inhibitor on the surface of steel occurs via both physical and chemical adsorptions.

\section{REFERENCES}

1. I.B. Obot, I. B. Onyeachu, J. Mol. Liq. 249, 83 (2018).

2. I.B. Obot, N.K. Ankah, A.A. Sorour, Z.M. Gasem, K. Haruna, Sust. Mater. Technol. 14, 1 (2017).

3. H. J. Habeeb, H. M. Luaibi, R. M. Dakhil, A. A. H. Kadhum, A. A. AlAmiery, T. S. Gaaz, Results Phys. 8, 1260 (2018).

4. A.M. Eldesoky, S.G. Nozha, Chin. J. Chem. Eng. 25, 1256 (2017).

5. R.W. Bosch, J. Hubrecht, W.F. Bogaerts, B.C. Syrett, Corrosion 57, 60 (2001).

6. M. H. Othman Ahmed, A. A. Al-Amiery, Y. K. Al-Majedy, A. A. H. Kadhum, T. S. Gaaz, Results Phys. 8, 728 (2018).

7. H. J. Habeeb, H. M. Luaibi, T. A. Abdullah, R. M. Dakhil, A. A. Al-Amiery, Case Studies in Thermal Engineering 12, 64 (2018).

8. C. Wang, L. Wu, F. Xue, R. Ma, W. Ke, J. Mater. Sci. Technol. 34, 1876 (2018).

9. N. Palaniappan, L. Raju Chowhan, S. Jothi, I.G. Bosco, I.S. Cole, Surf. Interf. 6, 237 (2017).

10. G. Golestani , M. Shahidi, D. Ghazanfari, Appl. Surf. Sci. 308, 347 (2014),

11. Y.J. Tan, J. Corros. Sci. Eng. 1, 11 (1999).

12. B.P. Markhali, R. Naderi, M. Mahdavian, J. Electroanal. Chem. 714-715, 56 (2014).

13. R.C. Nascimento, L.B. Furtado, M. J. O.C. Guimarães, P. R. Seidl, J.C. Rocha, J.A.C. Ponciano, M.T.M. Cruz, J. Mol. Liq. 256, 548 (2018).

14. K. Haruna, I.B. Obot, N.K. Ankah, A.A. Sorour, T.A. Saleh, J. Mol. Liq. 264,515 (2018).
15. E. Ituen, O. Akaranta, A. James, J. Taibah University for Science 11, 788 (2017).

16. M.A. Hegazy, A.Y. El-Etre, M. El-Shafaie, K.M. Berry, J. Mol. Liq. 214, 347 (2016).

17. M.A. Deyab, K. Eddahaoui, R. Essehli, T. Rhadfi, S. Benmokhtar, G. Mele, Desalination 383, 38 (2016).

18. E. Ituen, O. Akaranta, A. James, J. Mol. Liq. 224, 408 (2016).

19. E.B. Ituen, A.O. James, O. Akaranta, Egyptian J. Petroleum 26, 745 (2017).

20. S. RameshKumar, I. Danaee, M. RashvandAvei, M. Vijayan, J. Mol. Liq 212, 168 (2015).

21. H. Nady, M.M. El-Rabiei, M.A. Migahed, M. Fathy, Z. Phys. Chem. 231, 1179 (2016).

22. J. Dahdele, I. Danaee, G. R. Rashed, J. Chil. Chem. Soc. 61, 3025 (2016).

23. N. Moussaoui, D. Zerouali, N. Bettahar, J. Chil. Chem. Soc. 61, 3018 (2016).

24. N. K. Bakirhan, A. Asan, N. Colak, S. Sanli, J. Chil. Chem. Soc. 61, 3066 (2016).

25. A. H. Ahmed, A. M. Hassan, H. A. Gumaa, B. H. Mohamed, A. M. Eraky, J. Chil. Chem. Soc. 63, 4180 (2018).

26. S.S. Abd El-Rehim, M.A. Deyab, H.H. Hassan, A.M. Shaltot, Z. Phys. Chem. 231, 1573 (2017).

27. A.R. Hoseizadeh, I. Danaee, M.H. Maddahy, Z. Phys. Chem. 227, 403 (2013).

28. I. Danaee, M. Gholami, M. RashvandAvei, M.H. Maddahy, J. Ind. Eng. Chem. 26, 81 (2015).

29. J.R. Macdonald, Solid State Ionics 13, 147 (1984).

30. I. Danaee, S. Noori, Int. J. Hydrogen Energy 36, 12102 (2011).

31. A. Becke, Phys. Rev. 38, 3098 (1988).

32. D. Becke, J. Chem. Phys. 98, 5648 (1993).

33. C. Lee, W. Yang, R. Parr, Phys. Rev. 37, 785 (1988).

34. J. H. Al-Fahemi, M. Abdallah, E. A.M. Gad, B.A.A.L. Jahdaly, J. Mol. Liq 222, 1157 (2016).

35. M. Gholami, I. Danaee, M. Maddahy, M. RashvandAvei, Ind. Eng. Chem. Res. 52, 14875 (2013).

36. A.R. Hoseinzadeh, I. Danaee, M.H. Maddahy, J. Mater. Sci. Technol. 29 , 884 (2013).

37. M.A. Amin, S.S. Abd El-Rehim, E.E.F. El-Sherbini, R.S. Bayyomi, Electrochim. Acta, 52, 3588 (2007).

38. N. Labjar, M. Lebrini, F. Bentiss, N. Chihib, S. El Hajjaji, C. Jama, Mater Chem. Phys. 119, 330 (2010).

39. A. R. Hosein Zadeh, I. Danaee, M. H. Maddahy, J. Mater. Sci. Technol., 29, 884 (2013).

40. A. R. Hosein Zadeh, I. Danaee, M. H. Maddahy, M. RashvandAvei, Chem. Eng. Comm., 201, 380 (2014).

41. I. Danaee, N. Bahramipanah, S. Moradi, S. Nikmanesh, J. Electrochem. Sci. Technol. 7, 153 (2016).

42. A. Moteshakker, I. Danaee, J. Mater. Sci. Technol. 32, 282 (2016).

43. H.R. Riazi, I. Danaee, M. Peykari, Met. Mater. Int. 19, 217 (2013).

44. H. Gerengi, H.I. Sahin, Ind. Eng. Chem. Res. 51, 780 (2012).

45. B.P. Markhali, R. Naderi, M. Mahdavian, M. Sayebani, S.Y. Arman, Corros Sci. 75, 269 (2013).

46. E. García-Ochoa, J. Genescan, Surf. Coat. Technol. 184, 322 (2004).

47. J. M. Sanches-Amaya, R.A. Cottis, F.G. Botana, Corros. Sci. 47, 3280 (2005).

48. J.Y. Huang, Y.B. Qiu, X.P. Guo, Corros. Eng. Sci. Technol. 45, 288 (2010).

49. D. Seifzadeh, H. Basharnavaz, A. Bezaatpour, Mater. Chem. Phys. 138, 794 (2013).

50. U. Bertocci, F. Huet, R.P. Nogueira, P. Rousseau, Corrosion 58, 337 (2002).

51. M. Hernandez, J. Genesca, Corros. Sci. 51, 499 (2009).

52. H. Ashassi-Sorkhabi, D. Seifzadeh, J. Appl. Electrochem. 38, 1545 (2008).

53. A.M. Homborg, T. Ting, X. Zhang, E.P.M. Van Westing, P.J. Oonincx, J.H.W. De Wite, J.M.C. Mole, Electrochim. Acta 70, 199 (2012).

54. Ł. Lentka, J. Smulko, Measurement, 131, 569 (2019).

55. M. A. Rubio, K. Bethune, A. Urquia, J. St-Pierre, Int. J. Hydrogen Energy, 41, 14991 (2016).

56. D. Seifzadeh, A. Bezaatpour, R. Asadpour Joghani, Prot. Met. Phys. Chem Surf. 52, 329 (2016)

57. J. J. Perdomo, P. M. Singh, Corros. Rev. 20, 359 (2002).

58. H. Jafari, I. Danaee, H. Eskandari, Trans. Indian Inst. Met. 68, 729 (2015).

59. H. Jafari, I. Danaee, H. Eskandari, M. RashvandAvei, J. Mater. Sci. Technol. $30,239(2014)$

60. H.G. Hosseini, S.F.L. Mertens, M.R. Arshadi, Corros. Sci. 45, 1473 (2003)

61. J. Flis, T. Zakroczymski, Electrochim. Acta 41, 1245 (1996).

62. S. Deng, X. Li, H. Fu, Corros. Sci. 53, 822 (2011).

63. I. Lukovits, E. Kalman, F. Zucchi, Corrosion 57, 3 (2001).

64. P. Udhayakala, J. Chem. Pharm. Res. 6, 117 (2014). 